\section{Drivers to implement the circular economy in born-sustainable business models: a case study in the fashion industry}

Drivers to circular economy in fashion BMs

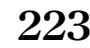

\author{
Cristina M. Ostermann, Leandro da Silva Nascimento,
} Fernanda Kalil Steinbruch and Daniela Callegaro-de-Menezes Management School, Federal University of Rio Grande do Sul, Porto Alegre, Brazil

\begin{abstract}
Purpose - This study aims to identify the drivers for adopting the circular economy (CE) in a born-sustainable business of the fashion sector.

Design/methodology/approach - An exploratory case study was carried out with a unique and relevant case: the only Brazilian company implementing circularity practices defined through a sectoral commitment, the 2020 Circular Fashion System Commitment.

Findings - From an analysis of the literature, a theoretical scheme composed of internal and external drivers is proposed. In the case studied, there is a prevalence of internal drivers that led the company to implement the CE. Most of the internal drivers described by the literature were identified in this research, except for two: profitability and available technology. Regarding the external drivers, of the 12 listed, only laws and regulations were identified. Thus, the results suggest that internal drivers are more numerous and may be more prominent than external ones for $\mathrm{CE}$ adoption in the born-sustainable business.

Research limitations/implications - Due to its exploratory design and unique case study, the research does not allow generalizations, suggesting replication with a larger number of companies and carrying out quantitative research with born-sustainable companies and incumbent companies, for comparison. Considering that there is a difference between companies that decide for sustainable practices and companies that were already born sustainable, it can be questioned if the drivers for implementing $\mathrm{CE}$ for both companies are also different.

Originality/value - This study proposes a theoretical scheme that indicates the main internal and external drivers for companies' CE implementation. Developed from a literature review and applied in an empirical case, this scheme is comprehensive and can be adopted to analyze companies of different sizes and industries. Hence, this paper generates new perspectives for CE literature.
\end{abstract}

Keywords Sustainability, Fashion, Drivers, Circular economy, Born-sustainable

Paper type Research paper

\section{Introduction}

There is a growing social, academic and governmental concern about the environmental impacts of the production and consumption linear economic model. This model has been considered not sustainable due to the resulting environmental and social effects (Ghisellini, Cialani \& Ulgiati, 2016; Korhonen, Honkasalo \& Seppälä, 2018a), such as the biodiversity decline and the global climate crises. Several actors have been mobilized to search for economic and productive solutions that reduce biological ecosystems' degradation process at

(C) Cristina M. Ostermann, Leandro da Silva Nascimento, Fernanda Kalil Steinbruch and Daniela Callegaro-de-Menezes. Published in Revista de Gestão. Published by Emerald Publishing Limited. This article is published under the Creative Commons Attribution (CC BY 4.0) licence. Anyone may reproduce, distribute, translate and create derivative works of this article (for both commercial and noncommercial purposes), subject to full attribution to the original publication and authors. The full terms of this licence may be seen at http://creativecommons.org/licences/by/4.0/legalcode
Received 12 March 2020 Revised 20 December 2020 10 March 2021

Accepted 29 March 2021 
REGE 28,3 the micro-, meso- and macro-levels (Kirchherr, Reike \& Hekkert, 2017; Prieto-Sandoval, Jaca \& Ormazabal, 2018).

At the micro-level, one observes, in recent years, the movement of already established companies to implement sustainable practices and the emergence of new companies that have already been born under the logic of sustainability. Businesses identified as "borngreen" or "born-sustainable" are guided by sustainability principles and built on pillars of collaboration and innovation, since their conception (Todeschini et al., 2017). Its processes and products are designed to be innovative and sustainable since birth (Isaak, 2016).

Some born-sustainable companies are choosing to implement circular practices in their business model. Even operating under the pillars of innovation and economic and social sustainability, these companies are making an effort to adopt specific measures focused on circularity. In sustainable practices, the circular economy (CE) is considered an alternative economic system that allows global sustainability (De los Rios \& Charnley, 2017; Murray, Skene \& Haynes, 2017). It is an economic model that seeks to reorganize the relationship between human economic activities and the environment, proposing a circularity logic in opposition to the current economic model (Geissdoerfer, Savaget, Bocken \& Jan, 2017). The CE can be a strategy for companies of all segments and sizes (Murray et al., 2017).

Different productive sectors, including the fashion industry, have been moving toward the implementation of $\mathrm{CE}$. The fashion industry is characterized by being one of the largest industries in the world, with the potential for environmental damage and significant social impacts due to the intensive use of natural resources in its production process (Armstrong et al., 2015) and its global production chain, with multiple agents and production outside the country of origin (Kozlowski, Bardecki \& Searcy, 2012).

Considering the economic and social relevance of the fashion industry and $\mathrm{CE}$ as one of the possible strategies for sustainability (Pieroni, McAloone \& Pigosso, 2019), this study aims to identify what are the drivers for adopting $\mathrm{CE}$ in a born-sustainable company operating in the fashion sector. To this end, an exploratory case study was carried out with the only Brazilian company that is implementing circularity practices defined through a sectoral commitment, called 2020 Circular Fashion System Commitment (Global Fashion Agenda, 2018).

The study is new concerning the analysis of empirical data on the drivers for implementing $\mathrm{CE}$ as a sustainability strategy in born-sustainable companies, considering that the existing studies on the transition to circular logic are directed to research in already established companies that decide to implement sustainability policies (Demirel, Li, Rentocchini \& Tamvada, 2017). It is also unprecedented for dealing with implementation drivers in the fashion sector: the identification of drivers in the fashion industry can contribute to the consolidation of circular practices in the sector.

$\mathrm{CE}$ is still an underexplored research area within the Brazilian context, and few studies explore the topic in this country. Some studies examine CE practices in the Brazilian context, but none has explored the fashion sector. For example, Paes, Medeiros, Mancini, Ribeiro \& Oliveira, (2019) analyze how municipal solid waste management systems' improvements can foster the implementation of CE in urban areas. Sehnem, Ndubisi, Preschlak, Bernardy \& Junior, 2020 explored wine chain CE practices related to the CE business model. Silva, Shibao, Kruglianskas, Barbieri \& Sinisgalli (2019) explore the barriers to implementing CE practices, and Abuabara, Paucar-Caceres, \& Burrowes-Cromwell (2019) investigate coffee capsule consumption concerning the ethical enterprise, environmental stewardship and CE. Therefore, the present study, focusing on the Brazilian business environment, can contribute to the construction of $\mathrm{CE}$ theory by providing data from an emerging country, outside the area of greater coverage of the $\mathrm{CE}$, that is, the European Union and China (Ghisellini et al., 2016; Mathews \& Tan, 2011; Murray et al., 2017). 


\section{Theoretical background}

To support the proposed discussion, it is necessary to understand the existing theoretical bases on $\mathrm{CE}$, sustainable fashion and drivers for adopting circularity.

\subsection{Circular economy and fashion industry}

By definition, $\mathrm{CE}$ is a sustainability strategy instead of the predominant logic in the modern economic system, known as linear (Mattos, Lourenço \& Albuquerque, 2018). It emerges as a new paradigm in systems, economics, value, production and consumption and proposes reorganizing the relationship between human economic activities and the environment (Murray et al., 2017). The CE considers business organizations as part of a comprehensive system and that its actions and decisions must balance economic development with the protection of the environment and social interests.

It proposes the radical transformation of production and consumption systems through greater efficiency in using resources and waste, reducing or eliminating losses in the process (Camacho-Otero, Boks \& Pettersen, 2018; Geissdoerfer et al., 2017). Therefore, it is based on regenerative systems, on the design of long-lasting products and processes and on the adoption of maintenance, repair, reuse, remanufacturing, reconditioning and recycling practices (Geissdoerfer et al., 2017). It proposes redesigning the production and consumption process, from the stage of conception, product design, supply chain development, production, distribution chain, consumption and disposal or reuse (Murray et al., 2017).

The academic literature presents a diversity of CE concepts (Korhonen, Nuur, Feldmann \& Birkie, 2018b; Prieto-Sandoval et al., 2018). One of the most known efforts in conceptualizing the CE is the one made by McDonough \& Braungart (2002). The authors propose a new industrial system in which materials return to the productive cycle many times to bring it back to the biological or technical process. With this practice, it becomes possible to eliminate the concept of garbage and raise the value of raw materials. For this research, $\mathrm{CE}$ is considered "a regenerative system in which the entry of resources and waste, emission and loss of energy is minimized by the deceleration, closing and narrowing of material and energy circuits" (Geissdoerfer et al., 2017, p. 766).

The CE is a strategy for sustainability (Pieroni et al., 2019), and the fashion industry has made significant moves to implement circular practices (Pedersen, Gwozdz \& Hvass, 2018). This industry operates in a fast fashion business model, which is the dominant logic and has driven the sector's growth (Kozlowski et al., 2012). It is based on high-scale production, short product cycle, consumption of fashion items of little durability, short lifespan, rapid psychological obsolescence and fast disposal, resulting in excessive consumption and increasing impacts (Armstrong et al., 2015; Kozlowski et al., 2012; Todeschini et al., 2017).

The fashion industry operates in a complex, fragmented, global chain (Kozlowski et al., 2012), impacting the three dimensions considered bases of sustainability: economic, social and environmental. Due to the outsourcing of production processes, the practice of offshore production, especially in developing countries, and the use of intensive labor, the sector faces challenges related to unethical work practices, such as exploitation of child and slave labor and production under inadequate working conditions (Turker \& Altuntas, 2014). In the environmental dimension, the clothing production process has severe environmental impacts on the product's life cycle, from the raw material extraction process, natural resources used to the care and maintenance of parts and disposal (Armstrong et al., 2015).

\subsection{Drivers for implementing the circular economy}

The motivating factors for implementing the $\mathrm{CE}$ are part of an interrelational system: in general, it is not a factor that acts alone, but a set of combined elements, resulting in specific conditions in each local context (Ranta, Aarikka-Stenroos, Ritala \& Makinen, 2018; Tura,

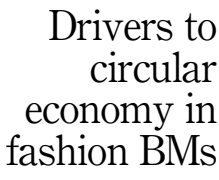


REGE 28,3
Hanski, Ahola, Ståhle \& Piiparinen, 2019). Thus, the factors are not mutually excluding and can act together and concomitantly (Jesus \& Mendonça, 2018).

They can be internal or external (Agyemang, Kusi-sarpong \& Mani, 2018; Govindan \& Hasanagic, 2018; Mattos et al., 2018). Mattos et al. (2018) consider as internal factors the organizational culture, the team's commitment to sustainability issues and $\mathrm{CE}$ and the support of the stakeholders who share the same values, with the company's participation in a group that is implementing $\mathrm{CE}$, such as sector, industry or companies of the same geographical location. Govindan \& Hasanagic (2018) pointed out as internal drivers the gains related to product development and the consequent increase in the efficiency of materials, the use of energy in the production process and the value of products resulting from the improvement of their quality.

Agyemang et al. (2018) propose as internal drivers the possibilities of gaining with the implementation of the $\mathrm{CE}$, such as financial gains resulting from increased profitability and market share, a consequence of the potential of the $\mathrm{CE}$ in attracting consumers, increased consumer loyalty and increase in product quality. In terms of the production process, cost reduction, process stability, environmental safety and risk management of health and safety issues and increased efficiency in using resources are mentioned. The authors also describe the alignment of business principles with $\mathrm{CE}$ principles; the interest of managers in deepening their knowledge of $\mathrm{CE}$; innovation and technology availability as internal drivers.

Among the external drivers, it was possible to identify the following factors: government regulations, international competition, companies' social responsibility and stakeholders pressure (Agyemang et al., 2018), government support, legislation and geographical proximity (Mattos et al., 2018), politics and economics (regulations, economic growth), human and animal health, environment issues (global warming and reduced environmental impact) and society (consumer concern and reduced effect of consumption and urbanization) (Govindan \& Hasanagic, 2018).

Other authors number drivers for implementing $\mathrm{CE}$ without categorizing them to their environment. Rizos et al. (2016) indicate some factors that act as organizational facilitators to implement CE business models: the commitment of employees and managers, the participation in groups of companies in a supply chain with the same mentality or that share the same principles, the demand of customers for sustainable products or services, financial attractions, external recognition of business models oriented to sustainability, personal knowledge of managers on the subject and government support.

As the primary motivating factor for implementing the $\mathrm{CE}$ by companies, Moktadir, Rahman, Rahman, Ali \& Paul (2018) indicate government regulation. The authors highlight the implementation of practices in the production chain and the possibility of creating a global competitive advantage resulting from economic benefits and the adoption of circular practices by other countries as factors for their implementation. Another driver would be the company's knowledge, its employees and the supply chain about $\mathrm{CE}$ and its benefits; leadership and commitment from top management and consumer concern.

Jesus \& Mendonça (2018) classify the drivers that motivate CE's transition as light or heavy. Heavy factors concern technical and economic issues, such as availability of technology that facilitates the optimization of resources, remanufacturing and regeneration; conditions for joint development with consumers of shared solutions; demand trends (increased demand and consequent scarcity of natural resources) and trends in the availability of raw materials (increase in the cost of natural resources and volatility) and production (stability and cost reduction). Light factors, on the other hand, concern institutional and social aspects. Institutional factors are the regulation of environmental issues through legislation, the increase in environmental protection standards and governmental guidelines on waste management. Social and cultural factors consist of the social concern about preserving the environment, greater education and information from society on environmental issues and the change in consumer behavior patterns (Jesus \& Mendonça, 2018). 
Tura et al. (2019) classify the drivers into environmental, economic, social, institutional, technological/informational, organizational and the ones that originated from the supply chain. Environmental factors result from global trends that aim to minimize adverse environmental impacts and scarcity of resources. The economic factors - identified as barriers to a new business - are related to cost reduction, the potential to create value from waste and secondary production flows and the potential for development. Social drivers include increasing awareness of sustainability needs and rising demand for sustainability, while institutional drivers embrace government and industry laws and regulations. The group of technological/informational factors includes emerging process technologies that support the CE business and enable new services and processes. The supply chain also contributes to increasing transparency and the availability of knowledge and technological resources through collaboration. Finally, the organizational facilitators are i) brand gains that CE promote, ii) changes in the organizational structure, strategy and culture to support the $\mathrm{CE}$, iii) development of skills and capabilities, iv) flexible decision-making and v) product or service development models.

Table 1 presents the theoretical scheme developed for this study. It offers the systematization of the drivers found in the theoretical review and the dimensions and categories used to analyze the research data. The factors were first classified into dimensions (internal or external), following the classification previously used by Agyemang et al. (2018), Govindan \& Hasanagic (2018) and Mattos et al. (2018), and then aggregated into "categories" by affinity.

\subsection{Born-sustainable companies and circularity}

Companies born under the sustainable logic are usually known as born-sustainable, borngreen, green startups, green-green business, sustainability entrepreneurs, eco-enterprises or green enterprises (Demirel et al., 2017; Isaak, 2016; Jayaratne, Sullivan Mort \& D'Souza, 2019; Klewitz \& Hansen, 2014; Todeschini et al., 2017). There are different discussions in the literature on the definition of "sustainable". In this study, we follow the concept described by Belz \& Binder (2017). These authors argue that, before being considered sustainable, a company must follow the triple bottom line of environmental, social and economic principles of sustainability. This aligns with the very definition of sustainable development, which simultaneously covers social inclusion, environmental conservation and economic prosperity (Sachs, 2000, 2004). Thus, born-sustainable companies are businesses designed to be sustainable from birth, based on the values and principles of sustainability, collaboration and innovation (Isaak, 2016; Todeschini et al., 2017). This understanding is necessary, given that some businesses may call themselves sustainable and adopt marketing tools to inform consumers and other stakeholders when they are not. This practice is considered a "greenwashing" process (Baldassarre \& Campo, 2016; Delmas \& Burbano, 2011). However, born-sustainable businesses are based on the three pillars of sustainability, which are verified through the evaluation of products, processes and organizational documents (e.g. sustainability reports).

Born-sustainable companies present innovative sustainability-derived goods, processes, services and practical solutions to social and environmental problems. They are said to be pioneers in applying new technologies in their areas, with a greater propensity for disruptive and radical innovations (Jayaratne et al., 2019; Klewitz \& Hansen, 2014). These companies operate in niches such as sustainability-oriented, potentially profitable and technologically challenging and, due to their innovative activity, work in environments of uncertainty and risks (Mrkajic, Murtinu \& Scalera, 2019).

In general, they emerge from initiatives by individual entrepreneurs, linked to the academy or spin-offs (Demirel et al., 2017). The knowledge about sustainable development allows companies to produce innovations, including those offered in traditional markets
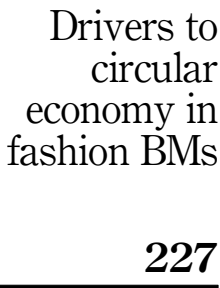


\section{REGE 28,3}

\begin{tabular}{|c|c|c|c|}
\hline Dimension & Category & Driver & References \\
\hline \multirow[t]{9}{*}{ Internal } & \multirow[t]{2}{*}{ Business } & Profitability & $\begin{array}{l}\text { Jesus \& Mendonça (2018), Tura et al. } \\
\text { (2019) and Agyemang } \text { et al. (2018) }\end{array}$ \\
\hline & & Market strategies & $\begin{array}{l}\text { Agyemang et al. (2018) and Tura et al. } \\
\text { (2019) }\end{array}$ \\
\hline & \multirow[t]{3}{*}{ Organizational } & Business principles & $\begin{array}{l}\text { Tura et al. (2019), Agyemang et al. (2018), } \\
\text { Mattos et al. (2018) and Rizos et al. (2016) }\end{array}$ \\
\hline & & $\begin{array}{l}\text { Top management and staff } \\
\text { commitment }\end{array}$ & Mattos et al. (2018) \\
\hline & & Knowledge & $\begin{array}{l}\text { Agyemang et al. (2018), Moktadir et al. } \\
\text { (2018) and Rizos et al., (2016) }\end{array}$ \\
\hline & \multirow[t]{2}{*}{ Operational } & $\begin{array}{l}\text { Productive process (cost } \\
\text { reduction, safety, stability and } \\
\text { efficiency) }\end{array}$ & $\begin{array}{l}\text { Agyemang et al. (2018), Govindan \& } \\
\text { Hasanagic (2018) and Jesus \& Mendonça } \\
\text { (2018) }\end{array}$ \\
\hline & & $\begin{array}{l}\text { Increased product and service } \\
\text { quality and efficiency }\end{array}$ & Govindan \& Hasanagic (2018) \\
\hline & \multirow[t]{2}{*}{ Technical Factors } & Available technology & $\begin{array}{l}\text { Tura et al. (2019) and Jesus \& Mendonça } \\
\text { (2018) }\end{array}$ \\
\hline & & Innovation & Agyemang et al. (2018) \\
\hline \multirow[t]{12}{*}{ External } & \multirow{5}{*}{$\begin{array}{l}\text { Government and } \\
\text { industry }\end{array}$} & Government incentives & Mattos et al. (2018) and Rizos et al. (2016) \\
\hline & & Laws and regulation & $\begin{array}{l}\text { Tura et al. (2019), Agyemang et al. (2018), } \\
\text { Govindan \& Hasanagic (2018), Jesus \& } \\
\text { Mendonça (2018) and Mattos et al. (2018) }\end{array}$ \\
\hline & & Network influence & Mattos et al. (2018) and Rizos et al. (2016) \\
\hline & & Supply chain & $\begin{array}{l}\text { Tura et al. (2019) and Moktadir et al. } \\
\text { (2018) }\end{array}$ \\
\hline & & Competitive global advantage & Moktadir et al. (2018) \\
\hline & \multirow[t]{5}{*}{ Social } & Economic growth & $\begin{array}{l}\text { Tura et al. (2019), Govindan \& } \\
\text { Hasanagic (2018) and Mattos et al. (2018) }\end{array}$ \\
\hline & & Consumer trends & $\begin{array}{l}\text { Jesus \& Mendonça (2018) and Rizos et al. } \\
\text { (2016) }\end{array}$ \\
\hline & & Social concern & $\begin{array}{l}\text { Tura et al. (2019), Agyemang et al. (2018), } \\
\text { Govindan \& Hasanagic (2018) and Jesus } \\
\text { \& Mendonça (2018) }\end{array}$ \\
\hline & & Education & Jesus \& Mendonça (2018) \\
\hline & & Human and animal health & Govindan \& Hasanagic (2018) \\
\hline & \multirow[t]{2}{*}{ Environmental } & $\begin{array}{l}\text { Trends in the availability of } \\
\text { natural resources }\end{array}$ & $\begin{array}{l}\text { Tura et al. (2019), Govindan \& } \\
\text { Hasanagic (2018) and Jesus \& Mendonça } \\
\text { (2018) }\end{array}$ \\
\hline & & Environmental impact & $\begin{array}{l}\text { Tura et al. (2019) and Govindan \& } \\
\text { Hasanagic (2018) }\end{array}$ \\
\hline
\end{tabular}

(Schaltegger \& Wagner, 2011). As a result, they present a high potential to transform sectors toward sustainability (Jayaratne et al., 2019).

They can be characterized as hybrid businesses, as their operation considers their social and environmental objectives equal to economic purpose and performance (Boyd, Henning, Reyna, Wang \& Welch, 2017). However, their main challenge is to align goals and social actions with economic returns (Hahn, Spieth \& Ince, 2018). These options may be antagonistic in some contexts, featuring trade-offs inherent to sustainability (Bansal \& Desjardine, 2014). They are innovative businesses guided with equal value by social, environmental and economic goals and may face scarce resources or difficulties in raising funds precisely because they seek a balance of profitability and environmental-social objectives (Demirel et al., 2017; Hall, Daneke \& Lenox, 2010). 
In short, the characteristics that identify a born-sustainable company are i) alignment of principles and value with sustainability and social concern (Boyd et al., 2017); ii) innovation (Isaak, 2016; Todeschini et al., 2017); iii) pioneering spirit (Klewitz \& Hansen, 2014); iv) operation in an environment of uncertainties and risks (Mrkajic et al., 2019); v) entrepreneurs connected to the academy and with in-depth knowledge on the topic (Demirel et al., 2017; Schaltegger \& Wagner, 2011) and vi) difficulty in balancing environmental goals and profitability (Hahn et al., 2018; Hall et al., 2010).

As much as the born-sustainable businesses models are relevant to the $\mathrm{CE}$ development and improvement, there is still no theoretical-empirical deepening on the drivers that lead these companies to adopt circularity practices, especially in the fashion industry. Table 1 shows the drivers indicated in the literature for $\mathrm{CE}$ implementation, but there is no consensus on the universality and their scope and specificities of these drivers. According to Demirel et al. (2017), the study on born-sustainable companies is still in its initial stage in academia. There are "unresolved issues" that should be clarified to help understand how green firms behave and perform. Also, it is essential to understand what constitutes "green" goods, services and processes, including to better understand them from the classifications and models used for the so-called "traditional" industries (Demirel et al., 2017).

In this sense, there is still no consensus in the literature that can indicate whether these drivers are only part of the reality of linear companies that decide to migrate to circularity or if they are also part of born-sustainable companies. Specifically, it is necessary to ask if all drivers are present in any born-sustainable company, and, if not, which are the most common or expressive motivators in these companies? This study seeks to deepen these questions through a case study with a born-sustainable company in this industry, keeping in mind the relevance of the fashion industry for sustainability.

\section{Methodological procedures}

To achieve the proposed objective of this article, exploratory research was made. The study consisted of two stages. The first stage was a review of the narrative literature concerning the drivers for implementing the $\mathrm{CE}$. The selection of the papers was nonsystematic, with no explicit criteria for inclusion and exclusion or protocols (Ferrari, 2015). The narrative review does not necessarily present a specific protocol (Rother, 2007) because the selection and analysis of the literature are based on the interpretation and subjective critical perspective of the researchers (Bernardo, Nobre \& Janete, 2004). Narrative reviews are commonly used to develop literature background sections in manuscripts with empirical investigations, such as this one. Therefore, the objective was not to expose all the papers that deal with the addressed theme here but highlight relevant aspects of the main papers that focus on drivers for the $\mathrm{CE}$ implementation. As a result, a theoretical scheme (presented in Table 1) was formulated. It guided the elaboration of the instrument of the research and the definition of the data analysis categories for the next stage.

In the second stage, the methodological strategy chosen was a single case study, based on the perception that the studied phenomenon's theoretical knowledge is limited and incipient. In this case, as suggested by Sigglekow (2007), the case study is indicated for exploring the theme and identifying other emerging themes. Furthermore, a single case study makes it possible to identify emerging phenomena that support the construction of new approaches or theoretical perspectives (Eisenhardt \& Graebner, 2007). This search for theoretical development is latent in the CE that lacks empirical investigations (Pieroni et al., 2019), given the emerging stage of this field of studies (Geissdoerfer et al., 2017).

It is a holistic case study because it has a single unit of analysis (a born-sustainable company) immersed in a specific context (fashion industry) (Yin, 2015). The analyzed case is the unit of analysis of the study (Yin, 2015). It seeks to identify the drivers for a born-

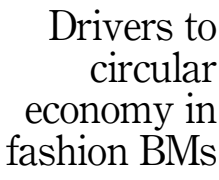

229 
REGE 28,3

sustainable company in the fashion industry to adopt circularity practices. For this purpose, the collection units covered both the individual and the organizational level (Yin, 2015). The collection centered on the owner who founded the company and on documents that could reveal the reasons for the company's circularity in this industry.

The combination of different collection techniques enabled the triangulation of data and the convergence of evidence, reinforcing the validity and reliability of the study (Yin, 2001). Thus, data about the company under investigation were collected using the following collection techniques: in-depth interview, documentation analysis and observation. Data collection took place between March and May of 2019. We characterize the data collection used in this paper as triangulation because of this combination of different information sources to analyze the same phenomenon. Data were collected in April 2019 and were aggregated to the research by analyzing the interview (primary source) and documents and observation. The documents analyzed were (1) the company's website and (2) reports issued by the Global Fashion Agenda. The observation occurred at a company event to launch the autumn-winter 2019 collection. The brand's customers were present, and there was an exhibition of the pieces from the collection and fashion show, with the presentation by the owners of the brand values and production techniques employed. The event was accompanied by a trained researcher, who recorded his observations about the brand, pieces, customers, environment and other issues relevant to research, being pertinent for better characterization of the company under study.

An in-depth semi-structured interview was conducted with one of the owners of the studied company. The interview script was prepared based on the theoretical scheme developed for the study (Table 1) and included questions about motivations, adoption, planning and CE process implementation. The interview was conducted at the company's headquarters. It lasted $1 \mathrm{~h} 04 \mathrm{~m}$, and it was recorded, transcribed (resulting in 11 pages of transcription) and analyzed. For the transcription, the denaturalized transcription technique was adopted based on the researchers' reflexivity. Nascimento \& Steinbruch (2019) stated that this transcription technique is adequate to support the data content analysis method.

The analytical approach is an adaptation of the thematic content analysis proposed by Bardin (2016). It was based on a list of codes that emerged from the literature and were modified from the empirical analysis, representing the categories identified in the textual data (Table 2). For analysis and categorization of the interview data, the NVivo 12 Pro program was used. The researchers then analyzed and reanalyzed the data in an iterative analytical process that ensured greater reliability to the findings (Gioia, Corley \& Hamiltom, 2013). This iterative process occurred throughout the stages of thematic content analysis, characterized by preanalysis, exploration and treatment of results and inference and interpretation of the evidence to categorize findings (Bardin, 2016). The analysis made it possible to verify whether the categories proposed in Table 1 were present in the company, but not all

\begin{tabular}{lll}
\hline Type & Category & Drivers \\
\hline Internal & Business & Market strategies \\
& Organizational & Business principles \\
& Commitment of senior management and staff \\
& Operational & Know-how \\
& Productive process \\
& Technical factors & Product/service \\
External & Government and industry & Laws and regulation \\
Source(s): Elaborated by the authors &
\end{tabular}

Table 2.

Source(s): Elaborated by the authors 
categories were present in the analyzed case. The categories identified empirically are in Table 2.

Methodological triangulation was composed of different evidence sources and distinct collection techniques, contributing to research reliability and validity (Bruning, Godri \& Takahashi, 2018). The researchers' self-reflexivity was adopted during all stages of the research, from the construction of the literature review to the case selection and the collection and analysis of the data (Tracy, 2010). This allowed deepening the critical evaluation of the case study, mainly about the results, ensuring greater rigor for this research through the systematic comparison of the structure literature that contributed to internal validity and through an inclusive approach to the theoretical perspectives on the drivers for $\mathrm{CE}$ adoption in light of born-sustainable companies, which contributed for external validity (Villarreal, 2017).

\subsection{Case study characterization}

This study examines a born-sustainable company in a formal and organized process of implementing the $\mathrm{CE}$, not only with its intention. The company object of study is the only Brazilian fashion company participating in the 2020 Circular Fashion System Commitment.

The Global Fashion Agenda is a non-profit organization, created by the main world leaders in the fashion sector to implement sustainability practices in the industry, especially $\mathrm{CE}$. The mission is to guide and support the industry for changes in fashion production, marketing and consumption. In 2017, the document 2020 Circular Fashion System Commitment was proposed to accelerate the transition of the fashion industry from the predominant fast fashion system to a circular fashion system, with sustainability practices through circularity strategies (Global Fashion Agenda, 2018). The pact was signed by 94 companies and adopted concrete measures and monitoring the progress of implementing the targets. The signatory companies represent $12.5 \%$ of the global fashion market and have major companies in the sector such as ASOS, H\&M, Nike, Inditex, Kering and Target (Global Fashion Agenda, 2018). Therefore, this document outlines the formal fashion industry guidelines for the implementation of the CE (Global Fashion Agenda, 2018).

Companies that have signed the document are committed to boosting CE's four main areas in its operation: design, collection, reuse and recycling. Through the commitment, the study's company is being monitored by formal objectives and indicators defined by the industry. Thus, as the only Brazilian company that is part of the 2020 Circular Fashion System Commitment, this case becomes unique and relevant for analyzing drivers for implementing the $\mathrm{CE}$. This single case selection is justified because this is a representative case in a specific community.

The case under study is a small southern Brazilian company, operating in the women's clothing market since 2010. It is a born-sustainable enterprise that uses innovation to combine fashion and sustainability and align environmental, social and economic values. The value creation proposition and the alignment of social, economic and environmental values differentiate green from a traditional enterprise (González-Serrano, AñóSanz \& GonzálezGarcía, 2020). The company defines itself as an ethical fashion company with a slow fashion philosophy. The main sustainability strategies are focused on the circular economy principles (Ellen MacArthur Foundation, 2021; Ghisellini et al., 2016): designing out waste and pollution, keeping products and materials in use by reduction, reuse, recycle and regenerating natural systems design. The garments' designs are timeless, seeking the extension of clothing lifetime. The production is without residues by using recycled post-consumer textile fibers and utilizing production wastes as supplies for other pieces, accessories or art pieces (designing out waste and pollution). The use of material residues generates new goods of equal or greater value, usefulness or quality of the original material (reduction, reuse and

\author{
Drivers to \\ circular \\ economy in \\ fashion BMs
}


REGE 28,3

\section{2}

recycle). The company uses a nontoxic printing technique, which does not require water for the process, and develops new uses of materials (regenerating natural systems design).

\section{Results}

The data collection sought to identify the drivers for implementing the CE by a bornsustainable business operating in the fashion sector. To this end, evidence was sought to classify the company under study as a born-sustainable company. Concerning the company's main values, it was identified in the results of the three collection techniques that the processes are designed sustainable from the beginning of the company. In the documentation analyzed, the company's values are presented in three categories: environmental, social and economic values, reinforcing the commitment to sustainability. In the event observed, the owners also emphasized the "born-sustainable" brand and differential in the public presentation. Finally, in the interviewee's speech, it is also noticed:

(...) the brand was born with this DNA of design because we believe that the piece also has to have designed (...) Ecology is the environmental issue, but there is the social issue, the economic issue. (interviewee).

The owners are academics and researchers in sustainable fashion, with a high level of formal knowledge about fashion and sustainability. According to the interviewee, "the company emerged from these investigations, to put theory into practice, related to sustainability". In alignment with the interviewee's speech, the documentation describes that the company "was born as a research company, in which the two partners, designers, (...) who are also researchers, apply sustainable fashion theories in practice”. Documentation also highlights the company's innovation proposition: "the pieces are designed through artistic processes to establish new relationships in use". This emphasis was also noticed on observation.

The paradoxes and difficulties inherent to born-sustainable companies, in particular the balance between environmental and social goals and the company's financial return, were identified in the interview:

(...) you have to think what a fair price is (...). The consumer must perceive value in the pieces, and by explaining the origin of the fabric, raw material, modeling, surface treatment, and all issues, the consumer will receive value in that (interviewee).

The data related to the drivers for implementing the $\mathrm{CE}$ were mostly identified in the interview. In the case studied, the number of internal factors was higher than external factors: 7 (seven) internal factors and 1 (one) external factor. Concerning internal factors, it was possible to identify drivers in all four suggested categories: business, organizational, operational and technical factors.

In the business category, the interviewee highlighted that business strategies are motivators to implement the CE. However, when asked if profitability would act as drivers, the interviewee answered negatively: "Honestly, I don't believe much, I think it is very difficult. I would like to, but I do not believe that it will be a motivating factor to increase our profitability".

In the organizational category, the three factors that are part of the category were positively identified by the interviewee as drivers. Regarding the operational category, the interviewee identified the two factors that make up the category as drivers.

About the technical factor category, the available technology was identified as a barrier to the adoption of circular practices, especially concerning the standard of the equipment used for production, designed for high volume production and the technology available for the practices of circularity that requires raw materials different from the ones usually used. Regarding the innovation factor, it was identified that innovation is a factor that motivated 
the implementation of $\mathrm{CE}$ in the case studied. From the speeches, it appears that the search for innovative sustainability practices was the main driver for the implementation of the $\mathrm{CE}$ by this company:

I think we are restless by nature on this issue of sustainability. We are always trying to grow, evolve. I think everything new is more difficult. We are pioneers in the sustainable fashion area. (interviewee).

Regarding the external drivers, importing countries' requirements, linked to the laws and regulations of those countries, were the only external drivers reported by the interviewee. The laws and regulations of the company's home country, Brazil, were not mentioned as drivers. When asked about the factors of government incentives and network influence, the answer was textually negative for the factors. The network was described as a strategy for exchanging information but without influencing the decision to implement circular practices. The supply chain was described as a barrier to the implementation of the $\mathrm{CE}$. The interviewee reported difficulties concerning the supply of raw materials for production within circularity practices, which differ from current industry standards, and difficulties in the sales process, especially related to shopkeepers. The industry's current business model, influenced by the fast fashion model, seems to be a limiting factor and a barrier to the adoption of circular practices. According to the interviewee,

Store owners I try to work with, they don't even want to know, because they want to continue with that scheme of buying in Bom Retiro (neighborhood from São Paulo) pieces with slave labor, much cheaper, give a fashion air, do a fashion production, put an absurd profit margin, because that way they get a super high profit.

In the interviewee's opinion, consumers' search for sustainability concerns other sectors, such as food. In the fashion sector, consumer pressure for sustainability is still a trend. Responding to the question of whether consumer trends influence the company in adopting $\mathrm{CE}$, the interviewee stated:

(...) I don't know if I would say it's already a consumer trend (...) I think it is growing a lot, yes, but what I notice is that it is still much more within brands and academia than with consumers.

Since the external factors related to the social and environmental categories are already inherent to the company's operation, the interviewee could not identify them as a driver. Asked if social and environmental issues were motivating the implementation of $\mathrm{CE}$, the interviewee replied:

All of this is inherent, we have been working since the beginning (...) since the beginning we have already looked for more sustainable raw materials and processes, this issue of respect for people (...), so I think that for us this was not after the Circular Economy, it came before.

The following section shows the study's findings and important themes that emerged from the results.

\section{Discussion}

The research sought to identify the drivers for implementing the $\mathrm{CE}$ by a born-sustainable company throughout a unique and relevant case study of a company in the fashion sector. It was possible to identify both internal and external drivers, as described in the literature. In the case studied, there is a prevalence of internal drivers that led the company to implement the CE.

It was possible to identify most of the internal drivers described by the literature, except for two: profitability and available technology. Thus, the results suggest that internal factors are more numerous in the case studied and may be more prominent than external factors.

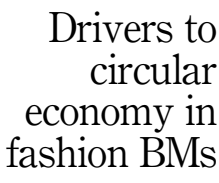

233 
REGE 28,3
The external factors showed less alignment with factors identified in the literature review. Among 12 listed factors, only one - laws and regulations - was indicated as a driver (Agyemang et al., 2018; Govindan \& Hasanagic, 2018). The supply chain, described in the literature as a driver (Tura et al., 2019; Moktadir et al., 2018), was identified as a barrier. This result can be analyzed by the lens of the dominant business model in the fashion industry, based on fast fashion, which requires short production times, speed, high volumes and low cost (Koszewska, 2018; Kozlowski, Searcy \& Bardeckir, 2015). Thus, productive technology and current practices in the supply chain are related to this type of demand, with machinery and processes that seek to produce large quantities at low costs (Kozlowski, Searcy \& Bardeckir, 2016; Lueg, Pedersen \& Clemmensen, 2013).

In addition to the dominant business logic, the activities of small and medium-sized companies are "typically determined by large firms they provide for in supply chains" (Demirel \& Danisman, 2019, p. 1610). For the implementation of circular practices in the fashion industry, a change in the technology structure and the supply chain as a whole is necessary to make production on a smaller scale and with greater added value. However, this change demands a shift in the industry's business model and profound changes in the structure of the production chain and consumption habits (Gwozdz, Nielsen \& Müller, 2017).

The influence of the network was not identified as a driver in the case studied. Again, one can assume that the current business model, added to the concentration of the industry in global competitors (Lueg et al., 2013), diminishes or neutralizes the influence of the network.

The consumer gains greater prominence in the CE due to closed cycles and recycling, remanufacturing and maintenance practices (Camacho-Otero et al., 2018). However, in the fashion area, the consumer market's pressure was weakly identified, still, as a behavior trend, not being classified as a driver for the implementation of circular practices.

The external factors that compose the social and environmental categories were not identified as drivers, as they are already intrinsic to born-sustainable companies' operations. The available studies on the topic that served as the basis for the categories of the research and factors sought to verify the driver for already established companies that intend to implement the CE. Thus, the present research results suggest that, in the context of bornsustainable companies, the concern with social and environmental issues is obvious and motivates not the implementation of circular practices but the existence of the company. Since CE is a sustainability strategy (Geissdoerfer et al., 2017; Murray et al., 2017), the drivers linked to the environment and society are the basis of born-sustainable companies (Boyd et al., 2017) because, without it, they do not exist.

Relating the data to the theoretical scheme proposed in the theoretical background (Table 1), the drivers for implementing the CE by born-sustainable companies identified in the research are in Table 2.

Regarding the company's characterization as born sustainable, the main characteristics described in the literature were identified in the case. Innovation as a driver aligns with that as suggested by Klewitz \& Hansen (2014). Born-sustainable companies are pioneers in applying new technologies in their areas, with a greater propensity for disruptive and radical innovations. According to Todeschini et al. (2017), these are companies with a base in innovation as part of their business model.

Finally, an important issue not addressed by previous research is the difficulty in operating its circular business model in the dominant logic of the linear system. Both the supply chain and consumers have linear production and purchasing patterns. Thus, bornsustainable business models in the fashion industry will challenge consumers by educating them regarding the value of their product and transmitting environmental and social values and principles to the chain. Other stakeholders also need to be involved in the process due to the circular system's characteristics (Geissdoerfer et al., 2017). The interaction with 
established companies can be an interesting way to boost this movement, as suggested by Todeschini et al. (2017), as well as educational measures and public policies to encourage the adoption of circular practices.

\section{Final remarks}

The research identified the drivers for implementing the $\mathrm{CE}$ by a born-sustainable company in the fashion industry. Based on the exposed data, the main findings reveal that, concerning internal drivers, there was alignment with the existing academic body of knowledge. For external drivers, on the other hand, the results suggest that born-sustainable companies might be influenced by different factors than those described in the literature. Thus, it suggests that there might have differences between the drivers for implementing the $\mathrm{CE}$ by born-sustainable companies and by incumbent companies.

The findings of the present research are rich in their academic contribution. First, it collaborates for the advancement of the acknowledgment about born-sustainable companies and the progress in this research field, as proposed by Demirel et al. (2017). This work also contributes to advancing the academic body of knowledge related to the $\mathrm{CE}$ insofar as it explores the drivers for its implementation in a specific type of company. According to Demirel \& Danisman (2019), small- and medium-sized enterprises (SMEs) are primarily responsible for business flows and job creation in Europe. The CE is still a drastic change in incumbent companies' operations and can present an opportunity for green entrepreneurs (Demirel \& Danisman, 2019). This economic and social importance, and the potential of born-sustainable companies to transform sectors toward sustainability (Jayaratne et al., 2019), make it essential to understand the peculiarities and drivers to implement the $\mathrm{CE}$ in born-sustainable companies.

Additionally, this research contributes to the proposition of a theoretical scheme (Table 1) that delimits the drivers for implementing $\mathrm{CE}$ from the literature, which can be applied in different sectors and industries and born-sustainable companies or not for a better understanding of motivations that lead these companies to become circular.

This research also provides subsidies for government and sector policies to encourage the implementation of circular practices. According to Ormazabal, Prieto-Sandoval, Jaca \& Santos (2016) and Demirel \& Danisman (2019), the support given by governments and policymakers is essential to the implementation of $\mathrm{CE}$ by small and medium businesses. The research results are aligned with this and reinforce the importance of public investment and funding strategies for CE business and solutions (Demirel \& Danisman, 2019).

In the managerial dimension, this research can collaborate with the implementation of $\mathrm{CE}$ initiated by the sector. The 2020 Circular Fashion System Commitment is the official document that outlines the fashion industry guidelines for implementing the CE (Global Fashion Agenda, 2018). Therefore, the findings can support sector initiatives involving the entire supply chain and stimulate $\mathrm{CE}$ implementation by small and medium companies.

Due to its exploratory design and unique case study, the research does not allow generalizations, suggesting replication with a larger number of companies and carrying out quantitative research with born-sustainable and incumbent companies for comparison. Considering that there is a difference between companies that decide on sustainable practices and companies that were already born-sustainable, it is possible to question whether the drivers for implementing the $\mathrm{CE}$ for both companies are also different.

We suggest future research to consider another context because the results could be different in countries where knowledge about the $\mathrm{CE}$ is more consolidated. There are effective public policies to regulate its implementation, such as the European Union and China. According to Sehnem, Campos, Julkovski \& Cazella (2019), Brazilian businesses tend to replicate practices adopted in other countries but adapted to the local context. The size of the

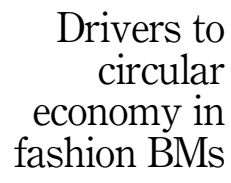

235 
REGE 28,3

\section{6}

company object of study (small) can also characterize specific drivers for this type of company.

It is also valuable to deepen the studies on the CE in the fashion industry, especially considering its organization in global chains, with large competitors that print the business' dominant logic and technology. The question concerning the importance and role of the chain is a relevant point for future study: understanding this second factor can assist in supporting the operation of sustainable fashion companies. Research on innovative business models oriented toward sustainability can help to understand the phenomenon of born-sustainable companies.

\section{References}

Abuabara, L., Paucar-Caceres, A., \& Burrowes-Cromwell, T. (2019). Consumers' values and behaviour in the Brazilian coffee-in-capsules market: Promoting circular economy. International Journal of Production Research, 57(23), 7269-7288, doi: 10.1080/00207543.2019.1629664.

Agyemang, M., Kusi-sarpong, S., \& Mani, V. (2018). Drivers and barriers to Circular Economy implementation: An explorative study in Pakistan's automobile industry. Management Decision, 57(4), 971-994, doi: 10.1108/MD-11-2018-1178.

Armstrong, C.M., Niinimäki, K., Kujala, S., Karell, E., \& Lang, C. (2015). Sustainable product-service systems for clothing: Exploring consumer perceptions of consumption alternatives in Finland. Journal of Cleaner Production, 97, 30-39, doi: 10.1016/j.jclepro.2014.01.046.

Baldassarre, F., \& Campo, R. (2016). Sustainability as a marketing tool: To be or to appear to be?. Business Horizons, 59(4), 421-429, doi: 10.1016/j.bushor.2016.03.005.

Bansal, P., \& Desjardine, M.R. (2014). Business sustainability: It is about time. Strategic Organization, 12(1), 70-78, doi: 10.1177/1476127013520265.

Bardin, L. (2016). Análise de conteúdo. São Paulo: Edições, 70.

Belz, F.M., \& Binder, J.K. (2017). Sustainable entrepreneurship: A convergent process model. Business Strategy and the Environment, 26(1), 1-17, doi: 10.1002/bse.1887.

Bernardo, W.M., Nobre, M.R.C., \& Janete, F.B. (2004). A prática clínica baseada em evidências. Parte II: Buscando as evidências em fontes de informação. Revista da Associação Médica Brasileira, 50(1), 104-108, doi: 10.1590/S0104-42302004000100045.

Boyd, B., Henning, N., Reyna, E., Wang, D., Welch, M., \& Hoffman, A.J. (2017). Hybrid Organizations: New Business Models for Environmental Leadership. Routledge, New York.

Bruning, C., Godri, L., \& Takahashi, A.R.W. (2018). Triangulation in case studies: Incidence, appropriations and misunderstandings in management studies. Administração: Ensino e Pesquisa, 19(2), 277-307, doi: 10.13058/raep.2018.v19n2.889.

Camacho-Otero, J., Boks, C., \& Pettersen, I.N. (2018). Consumption in the circular economy: A literature review. Sustainability, 10(8), 2758, doi: 10.3390/su10082758.

De los Rios, I.C., \& Charnley, F.J.S. (2017). Skills and capabilities for a sustainable and Circular Economy: The changing role of design. Journal of Cleaner Production, 160(September), 109-122, doi: 10.1016/j.jclepro.2016.10.130.

Delmas, M.A., \& Burbano, V.C. (2011). The drivers of greenwashing. California Management Review, 54(1), 64-87, doi: 10.1525/cmr.2011.54.1.64.

Demirel, P., \& Danisman, G.O. (2019). Eco-innovation and firm growth in the circular economy: Evidence from European small-and-medium-sized enterprises. Business Strategy and the Environment, 28(8), 1608-1618, doi: 10.1002/bse.2336.

Demirel, P., Li, Q.C., Rentocchini, F., \& Tamvada, J.P. (2017). Born to be green: New insights into the economics and management of green entrepreneurship. Small Business Economics, 52, 759-771, doi: 10.1007/s11187-017-9933-z. 
Eisenhardt, K.M., \& Graebner, M.E. (2007). Theory building from cases: Opportunities and challenges. Academy of Management Journal, 50(1), 25-32, doi: 10.5465/amj.2007.24160888.

Ellen MacArthur Foundation (2021). What is the circular economy?, available at: https://www. ellenmacarthurfoundation.org/circular-economy/what-is-the-circular-economy (accessed 5 February 2021).

Ferrari, R. (2015). Writing narrative style literature reviews. Medical Writing, 24(4), 230-235, doi: 10. 1179/2047480615Z.000000000329.

Geissdoerfer, M., Savaget, P., Bocken, N.M.P., \& Jan, E. (2017). The circular economy: A new sustainability paradigm?. Journal of Cleaner Production, 143, 757-768, doi: 10.1016/j.jclepro. 2016.12.048.

Ghisellini, P., Cialani, C., \& Ulgiati, S. (2016). A review on Circular Economy: The expected transition to a balanced interplay of environmental and economic systems. Journal of Cleaner Production, 114, 11-32, doi: 10.1016/j.jclepro.2015.09.007.

Gioia, D.A., Corley, K.G., \& Hamiltom, A.L. (2013). Seeking qualitative rigor in inductive research: Notes on the gioia methodology. Organizational Research Methods, 16(1), 15-31, doi: 10.1177/ 1094428112452151.

Global Fashion Agenda (2018). Signatories' targets June 2018 - 2020 circular fashion system commitment, available at: https://www.globalfashionagenda.com/final-chance-to-join-the-2020circular-fashion-system-commitment/ (accessed 23 November 2019).

González-Serrano, M.H., Añó Sanz, V., \& González-García, R.J. (2020). Sustainable sport entrepreneurship and innovation: A bibliometric analysis of this emerging field of research. Sustainability, 12(12), 5209, doi: 10.3390/su12125209.

Govindan, K., \& Hasanagic, M. (2018). A systematic review on drivers, barriers, and practices towards circular economy: A supply chain perspective. International Journal of Production Research, 7543, 1-34, doi: 10.1080/00207543.2017.1402141.

Gwozdz, W., Nielsen, K.S., \& Müller, T. (2017). An environmental perspective on clothing consumption: Consumer segments and their behavioral patterns. Sustainability, 9(5), 762, doi: 10.3390/su9050762.

Hahn, R., Spieth, P., \& Ince, I. (2018). Business model design in sustainable entrepreneurship. Journal of Cleaner Production, 176, 439-451, doi: 10.1016/j.jclepro.2017.12.167.

Hall, J.K., Daneke, G.A., \& Lenox, M.J. (2010). Sustainable development and entrepreneurship: Past contributions and future directions. Journal of Business Venturing, 25(5), 439-448, doi: 10.1016/j. jbusvent.2010.01.002.

Isaak, R. (2016). The Making of the Ecopreneur, Making Ecopreneurs. Routledge, Abingdon.

Jayaratne, M., Sullivan Mort, G., \& D'Souza, C. (2019). Sustainability entrepreneurship: From consumer concern towards entrepreneurial commitment. Sustainability, 11(24), 7076, doi: 10. 3390/su11247076.

Jesus, A.de, \& Mendonça, S. (2018). Lost in transition? Drivers and barriers in the eco-innovation road to the circular economy. Ecological Economics, 145, 75-89, doi: 10.1016/j.ecolecon.2017. 08.001 .

Kirchherr, J., Reike, D., \& Hekkert, M. (2017). Conceptualizing the circular economy: An analysis of 114 definitions. Resources, Conservation and Recycling, 127(September), 221-232, doi: 10.1016/j. resconrec.2017.09.005.

Klewitz, J., \& Hansen, E.G. (2014). Sustainability-oriented innovation of SMEs: A systematic review. Journal of Cleaner Production, 65, 57-75, doi: 10.1016/j.jclepro.2013.07.017.

Korhonen, J., Honkasalo, A., \& Seppälä, J. (2018a). Circular economy: The concept and its limitations. Ecological Economics, 143, 37-46, doi: 10.1016/j.ecolecon.2017.06.041.

Korhonen, J., Nuur, C., Feldmann, A., \& Birkie, S.E. (2018b). Circular Economy as an essentially contested concept. Journal of Cleaner Production, 175, 544-552, doi: 10.1016/j.jclepro.2017.12.111.

\section{Drivers to circular economy in fashion BMs}


REGE 28,3

\section{8}

Koszewska, M. (2018). Circular economy - challenges for the textile and clothing industry. Autex Research Journal, 18(4), 337-347, doi: 10.1515/aut-2018-0023.

Kozlowski, A., Bardecki, M., \& Searcy, C. (2012). Environmental impacts in the fashion industry: A life cycle and stakeholder framework. Journal of Corporate Citizenship, 45, 17-36, doi: 10.9774/ GLEAF.4700.2012.sp.00004.

Kozlowski, A., Searcy, C., \& Bardeckir, M. (2015). Corporate sustainability reporting in the apparel industry. International Journal of Productivity and Performance Management, 64(3), 377-397, doi: 10.1108/IJPPM-10-2014-0152.

Kozlowski, A., Searcy, C., \& Bardeckir, M. (2016). Innovation for a sustainable fashion industry: A design focused approach toward the development of new business models. Green Fashion: Springer. doi: 10.1007/978-981-10-0245-8.

Lueg, R., Pedersen, M.M., \& Clemmensen, S.N. (2013). The role of corporate sustainability in a low-cost business model - a case study in the scandinavian fashion industry. Business Strategy and the Environment, 24(5), 344-359, doi: 10.1002/bse.1825.

Mathews, J.A., \& Tan, H. (2011). Progress toward a circular economy in China: The drivers (and inhibitors) of eco-industrial initiative. Journal of Industrial Ecology, 15(3), 435-457, doi: 10.1111/j. 1530-9290.2011.00332.x.

Mattos, C.A.D, Lourenço, T., \& Albuquerque, M.D. (2018). Enabling factors and strategies for the transition toward a circular economy (CE). Sustainability, 10(12), 4628, doi: 10.3390/ su10124628.

McDonough, W., \& Braungart, M. (2002). Cradle to Cradle: Remaking the Way We Make Things. New York, NY: North Point Press.

Moktadir, M.A., Rahman, T., Rahman, M.H., Ali, S.M., \& Paul, S.K. (2018). Drivers to sustainable manufacturing practices and circular economy: A perspective of leather industries in Bangladesh. Journal of Cleaner Production, 174, 1366-1380, doi: 10.1016/j.jclepro.2017.11.063.

Mrkajic, B., Murtinu, S., \& Scalera, V.G. (2019). Is green the new gold? Venture capital and green entrepreneurship. Small Business Economics, 52, 929-950, doi: 10.1007/s11187-017-9943-x.

Murray, A., Skene, K., \& Haynes, K. (2017). The circular economy: An interdisciplinary exploration of the concept and application in a global context. Journal of Business Ethics, 140(3), 369-380, doi: 10.1007/s10551-015-2693-2.

Nascimento, L., \& Steinbruch, F. (2019). "The interviews were transcribed”, but how? Reflections on management research. RAUSP Management Journal, 54(4), 413-429, doi: 10.1108/rausp-052019-0092.

Ormazabal, M., Prieto-Sandoval, V., Jaca, C., \& Santos, J. (2016). An overview of the circular economy among SMEs in the Basque country: A multiple case study. Journal of Industrial Engineering and Management (JIEM), 9(5), 1047-1058, doi: 10.3926/jiem.2065.

Paes, M.X., Medeiros, G.A., Mancini, S.D., Ribeiro, F.M., \& Oliveira, J.A.P. (2019). Transition to circular economy in Brazil: A look at the municipal solid waste management in the state of São Paulo. Management Decision, ahead-of-print, doi: 10.1108/MD-09-2018-1053.

Pedersen, E.R.G., Gwozdz, W., \& Hvass, K.K. (2018). Exploring the relationship between business model innovation, corporate sustainability, and organisational values within the fashion industry. Journal of Business Ethics, 149(2), 267-284, doi: 10.1007/s10551-016-3044-7.

Pieroni, M.P.P., McAloone, T.C., \& Pigosso, D.C.A. (2019). Business model innovation for circular economy and sustainability: A review of approaches. Journal of Cleaner Production, 215, 198216, doi: 10.1016/j.jclepro.2019.01.036.

Prieto-Sandoval, V., Jaca, C., \& Ormazabal, M. (2018). Towards a consensus on the circular economy. Journal of Cleaner Production, 179, 605-615, doi: 10.1016/j.jclepro.2017.12.224.

Ranta, V., Aarikka-Stenroos, L., Ritala, P., \& Makinen, S.J. (2018). Exploring institutional drivers and barriers of the circular economy: A cross-regional comparison of China, the US, and Europe. Resources, Conservation and Recycling, 135, 70-82, doi: 10.1016/j.resconrec.2017.08.017. 
Rizos, V., Behrens, A., Van der Gaast, W., Hofman, E., Ioannou, A., Kafyeke, T., Flamos, A., Rinaldi, R., Papadelis, S., Hirschnitz-Garbers, M., \& Topi, C. (2016). Implementation of circular economy business models by small and medium-sized enterprises (SMEs): Barriers and enablers. Sustainability, 8, 1212, doi: 10.3390/su8111212.

Rother, E.T. (2007). Revisão sistemática X revisão narrativa. Acta paulista de Enfermagem, 20(2), 5-6, doi: 10.1590/S0103-21002007000200001.

Sachs, I. (2000). Sociedade, cultura e meio ambiente. Mundo and Vida, 2(1), 7-13.

Sachs, I. (2004). Desenvolvimento sustentável: Desafio do século XXI. Ambiente and Sociedade, 7(2), 214-216, doi: 10.1590/S1414-753X2004000200016.

Schaltegger, S., \& Wagner, M. (2011). Sustainable entrepreneurship and sustainability innovation: Categories and interactions. Business Strategy and the Environment, 20(4), 222-237, doi: 10. 1002/bse.682.

Sehnem, S., Campos, L.M.S., Julkovski, D.J., \& Cazella, C.F. (2019). Circular business models: Level of maturity. Management Decision, 57(4), 1043-1066, doi: 10.1108/MD-07-2018-0844.

Sehnem, S., Ndubisi, N.O., Preschlak, D., Bernardy, R.J., \& Junior, S.S. (2020). Circular economy in the wine chain production: Maturity, challenges, and lessons from an emerging economy perspective. Production Planning and Control, 31(11-12), 1014-1034, doi: 10.1080/09537287. 2019.1695914.

Sigglekow, N.J. (2007). Persuasion with case studies. Academy of Management Journal, 50(1), 20-24, doi: 10.5465/amj.2007.24160882.

Silva, F.C., Shibao, F.Y., Kruglianskas, I., Barbieri, J.C., \& Sinisgalli, P.A.A. (2019). Circular economy: Analysis of the implementation of practices in the Brazilian network. Revista de Gestão, 26(1), 39-60, doi: 10.1108/REGE-03-2018-0044.

Todeschini, B.V., Cortimiglia, M.N., Callegaro-de-Menezes, D., \& Ghezzi, A. (2017). Innovative and sustainable business models in the fashion industry: Entrepreneurial drivers, opportunities, and challenges. Business Horizons, 60(6), 759-770, doi: 10.1016/j.bushor.2017.07.003.

Tracy, S.J. (2010). Qualitative quality: Eight "big-tent" criteria for excellent qualitative research. Qualitative Inquiry, 16, 837-851, doi: 10.1177/1077800410383121.

Tura, N., Hanski, J., Ahola, T., Ståhle, M., \& Piiparinen, S. (2019). Unlocking circular business: A framework of barriers and drivers. Journal of Cleaner Production, 212, 90-98, doi: 10.1016/j. jclepro.2018.11.202.

Turker, D., \& Altuntas, C. (2014). Sustainable supply chain management in the fast fashion industry: An analysis of corporate reports. European Management Journal, 32(5), 837-849, doi: 10.1016/j. emj.2014.02.001.

Villarreal, O. (2017). Is it desirable, necessary and possible to perform research using case studies?. Cuadernos de Gestión, 17(1), 147-172, doi: 10.5295/cdg.140516ov.

Yin, R.K. (2001). Estudo de caso: Planejamento e métodos. Catalogação na publicação: mônica ballejo canto, Porto Alegre: Bookman, 2, doi: 10.1088/1751-8113/44/8/085201.

Yin, R.K. (2015). Case Study Research: Design and Methods, 5th edition. London: Sage.

\section{Interview script}

(1) How was the process of establishment of the company?

(2) What are the company's main values? What is the basis of your actions and goals?

(3) How is the relationship between environmental and social objectives versus financial objectives?

(4) What is Circular Economy in the fashion industry/business? 
REGE 28,3

\section{0}

(5) What were/are the main drivers that motivated the implementation of the Circular Economy?*

(6) How was the decision process to implement the Circular Economy?

(7) What Circular Economy processes are on their implementation process? How was/is the process going?

(8) In which factors are the operation in the logic of the Circular Economy different from the operation of a sustainable company?

(9) What are the main drivers (motivating factors, facilitators) for companies born sustainable (in general, from any area) to implement the Circular Economy, in your opinion?

* Interviewers asked each of the factors listed in Table 1 for this question.

\begin{abstract}
About the authors
Cristina M. Ostermann is PhD Student in Management, Management Scholl at the Federal University of Rio Grande do Sul (UFRGS), Brazil. Her main research interests include sustainability, circular economy, sustainable consumer behavior and marketing. Cristina M. Ostermann is the corresponding author and can be contacted at: cris.ostermann@gmail.com

Leandro da Silva Nascimento is Ph.D. Student in Management, Management Scholl at the Federal University of Rio Grande do Sul (UFRGS), Brazil. He holds a master's and bachelor's degree in Management from the Federal University of Pernambuco (UFPE), Brazil. His main research interests include sustainability, strategic management, social entrepreneurship and innovation.

Fernanda Kalil Steinbruch is Ph.D. Student in Management, Management Scholl at the Federal University of Rio Grande do Sul (UFRGS), Brazil. Her main research interests include international business, innovation and strategy.

Daniela Callegaro-de-Menezes, Ph.D. is a Professor of Innovation, Technology and Sustainability at the Management Scholl, the Federal University of Rio Grande do Sul. Her main research interests are innovation, consumer behavior, relationship marketing, loyalty, value co-creation, conscious consumption behavior, creative economy and agribusiness Their current project is wine, organic products and sustainable fashion.
\end{abstract}

Associate Editor: Ana Lucia Figueiredo Facin

For instructions on how to order reprints of this article, please visit our website:

www.emeraldgrouppublishing.com/licensing/reprints.htm

Or contact us for further details: permissions@emeraldinsight.com 